\title{
An Analysis of Japan's Quality Movement from the Meiji Period until the Present Day: A Synthesized Perspective
}

\author{
Svetoslav G. Georgiev* and Seiichi Ohtaki
}

\begin{abstract}
Manuscript type: Research paper

Research aims: This paper has a tri-fold purpose. First, we seek to establish whether Japan's focus on quality manufacturing was a conscious choice. Second, we attempt to analyse the impact of the external environment on the success/failure of quality upgrading. Third, we investigate whether Japanese businesses, regardless of the shifts in the competitive environment in the last two decades, continue to explore quality management as a strategic weapon for competitiveness.

Design/Methodology/Approach: The study is based on a systematic literature review using two of the main scientific databases - JSTOR and Emerald. The scientific papers used for this synthesis - over sixty manuscripts in total - have (predominantly) focused on the quality movement in Japan at a national/country level. These are peerreviewed articles published between 1980 and 2018 that go beyond the field of operations/quality management.

Research findings: We show that Japan's focus on quality upgrading was a conscious choice that sought to elevate the country's economy.
\end{abstract}

\footnotetext{
* Corresponding author: Svetoslav G. Georgiev is a Senior Lecturer at the Faculty of Business Administration - Ton Duc Thang University - Ho Chi Minh City, Vietnam. Email: svetoslav. georgiev@tdtu.edu.vn

Seiichi Ohtaki is a Professor at the Graduate School of Leadership and Innovation - Shizenkan University - Tokyo, Japan. Email: ohtaki@shizenkan.ac.jp

Acknowledgements: We gratefully acknowledge the support of Tohoku University (Sendai, Japan). The first-named author's contribution to this work was funded through the support of the Ministry of Education, Culture, Sports, Science and Technology (MEXT) while pursuing his master's and doctorate degree at Tohoku University.
}

https://doi.org/10.22452/ajba.vol13no2.3 
Moreover, we identify a number of external factors (e.g. government support, sound formal institutions) - four, specifically - that, according to our analysis, have been critical to Japan's success in quality manufacturing. Finally, we show that regardless of the (recent) shifts in the competitive environment, (product) quality improvement continues to take a central part in Japan's pursuit of global economic dominance.

Theoretical contribution/Originality: We claim that that this is the first comprehensive study of Japan's quality movement to include scientific data from the Meiji Period until the present day (so far the bulk of the scientific papers have focused on the quality movement in post-war Japan). We also bridge a substantial gap in the QM literature regarding the influence of the external environment (e.g. political factors, social factors) on the success/failure in quality upgrading.

Practitioner/Policy implication: The insights of this paper provide a valuable lesson to policy makers from developing and/or underdeveloped economies in their pursuit of economic growth. The study is also important to manufacturers from developing and/ or underdeveloped countries to understand their own quality management practices in comparison with those in Japan, which have the highest standards of manufacturing quality.

Research limitation/Implication: Our literature search is admittedly not exhaustive as it involves only two of the main scientific databases.

Keywords: Quality, Quality Management, Quality Movement, Economic Growth, Japan

JEL Classification: M11

\section{Introduction}

Japan's post-World War II (WWII) quality movement (also known as the quality revolution) has been analysed by numerous researchers including Hitomi (1985), Ishikawa (1985), Garvin (1986), Deming (1986), Juran and Godfrey (1999), Dahlgaard and Dahlgaard-Park (2006) and Fisher (2009) among others. From a manufacturer of cheap and shoddy goods up until the end of WWII, in less than thirty years, the Country of the Rising Sun become the world standard for quality manufacturing. As Japan's efforts in quality manufacturing started to capture the world's attention in the 1980s, it became clear that the Japanese had successfully challenged the common conviction (until then) that higher product quality results in a higher price (Mahon \& Dyck, 1982; Smith, 1993; Hamzah \& Ho, 1994). This paradigm shift - the ability to produce 
high quality goods at lower prices - became the centre of managerial and scientific analysis for the next twenty years or so. Consequently, the perennial question that vexed not just mangers and academics, but also economists and (even) politicians in the following years was: What is the genesis of the Japanese manufacturing excellence?

After decades of extensive research into this topic, the reasons behind Japan's success in quality manufacturing that came to the fore seem to be as numerous as the individuals who studied the country's quality movement. From a (conscious) focus on unique production processes and technologies (e.g. Mahon \& Dyck, 1982; Ferdows, Miller, Nakane, \& Vollmann, 1986) to mere luck yielded by a series of events (e.g. the US occupation in post-war Japan, the Korean War) (e.g. Creelman, 1993; De Miranda, 2003; Adams \& Miranti, 2008), there seems to be no universal explanation as to how Japan became what it is today - a country that is able to produce superior goods at higher rates of productivity (i.e. lower cost) than any of its most advanced competitors. This fundamental weakness can be explained by the fact that there has not been an attempt so far to synthesise all aspects (both internal and external) behind the success of Japanese manufacturing, we argue. Prompted by this gap in the quality management (QM) literature, we embarked on a mission in the first years of the last decade to provide a multifaceted analysis of Japan's quality movement and its postwar success. The starting point of this analysis was a book entitled The Economic Development of Japan: The Path Traveled by Japan as a Developing Country (Ohno, 2006). The focus of this study was also provoked by the (worrisome) emerging trend within academe that quality is no longer a competitive advantage - a premise that we strongly disagree with.

The declining number of QM-related citations in the literature since the beginning of the new century is (indeed) evident, as our study shows. This shift in focus is largely reasoned by the fact that the competitive landscape has moved away from QM towards innovation (e.g. new product development) and other competitive domains that stress novelty (Zhang \& Xia, 2013). At the same time, however, the limited in number, more recent studies, which have focused on the importance of higher product quality and effective QM systems as part of the (contemporary) competitive environment, reveal that quality has not lost its lustre and relevance in business. As Zeng, Phan and Matsui (2015) asserted, quality and current competitive dimensions such as innovation are not a matter of trade-off; on the contrary, they can coexist. Finally, some recent quality related issues coming from the business 
world including Samsung's smartphone "Galaxy Note 7" glitches, and Takata's (the Japanese airbag manufacturer) bankruptcy among other cases are also calling for a reconsideration of the importance of quality as part of the (contemporary) competitive environment, we argue.

This paper has a tri-fold purpose. First, we attempt to account for Japan's quality movement since the Meiji period until the present day by stressing the ongoing importance of product quality upgrading as a driver of economic growth (regardless of the current shift in competitive forces). Hence, our first research question (RQ) is: Was Japan's focus on quality upgrading a conscious choice? Second, by analysing Japan's quality movement at a national/country level, we also seek to address a perennial QM-related question regarding the influence of the external environment (e.g. political factors, social factors) on the success/failure in quality upgrading: What are the external (key) factors behind Japan's success in quality manufacturing/upgrading? Third, considering the shift(s) in the competitive environment since the start of the new century, we explore one more relevant question: Do Japanese businesses continue to explore QM as a strategic weapon for competitiveness (today)?

The study is based on a systematic literature review using two of the main scientific databases - i.e. JSTOR and Emerald. While the literature is replete with articles studying Japanese QM approaches such as TQM and Kaizen at an organisational level, the scientific papers used for this synthesis - over sixty manuscripts in total - have (predominantly) focussed on the quality movement in Japan at a national/country level. These are peer-reviewed papers published between 1980 and 2018, which look at the quality movement not only from a business and management perspective, but also from an economic and a socio-cultural one. Although our literature search is admittedly not exhaustive, we believe that it covers a significant portion of publications on the quality movement in Japan and thus is a useful source for quality management researchers and practitioners.

The results of our systematic literature review provide evidence for Japan's heightened awareness of the importance of quality upgrading as a driver of economic growth. Specifically, our study shows that Japan's focus on quality upgrading was a conscious decision that played a vital role in the country's economic growth. We also identify a number of external factors (e.g. government support, sound formal institutions) - four, specifically - that, according to our analysis, have been critical to Japan's success in quality manufacturing. Finally, we show that 
regardless of the (recent) shifts in the competitive environment, (product) quality improvement continues to take a central part in Japan's pursuit of global economic dominance.

This study contributes to the existing QM literature by ending an over three-decade debate as to how and why Japan become the world leader in quality manufacturing. We show that Japan's focus on quality upgrading was a conscious choice that sought to elevate the country's economy, thereby making it the second richest nation in the world (currently third). Moreover, we claim that that this is the first comprehensive study of Japan's quality movement to include scientific data from the Meiji Period until the present day (so far the bulk of the scientific papers have focused on the quality movement in post-war Japan). We also bridge a substantial gap in the QM literature regarding the influence of the external environment (e.g. political factors, social factors) on the success/failure in quality upgrading; to our knowledge, we are the first to do so. Finally, by demonstrating the importance of product quality upgrading as a driver of economic growth, as well as the resilience of Japan's quality manufacturing, we remind the scientific and practitioner communities of the importance of QM as a competitive advantage.

\section{Research Methodology}

In line with the aims of this research, we carried out a systematic literature review. Unlike traditional narrative reviews, "systematic reviews adopt a replicable, scientific and transparent process (i.e. a detailed technology) that seeks to minimize bias through exhaustive literatures searches of published and unpublished studies, and by providing an audit trial of the reviewers' decisions, procedures and conclusions" (Tranfield, Denyer, \& Smart, 2003, p. 209). Specifically, our paper presents a systematic literature review of scientific articles published between 1980 and 2018 in peer-reviewed journals. While the so-called quality revolution originated in the 1950s in Japan (Hill, 1989; Zhao, Maheshwari, \& Zhang, 1995), it was not until the 1980s when the West realised Japan's extraordinary leap in quality manufacturing (Vuppalapati, Ahire, \& Gupta, 1995; Dahlgaard \& Dahlgaard-Park, 2006). In fact, a number of academic works link the 1980s with several major QM-related themes with Japanisation and total quality management (TQM) being the ones that have received the most attention from researchers (Garvin, 1986; De Miranda, 2003). Moreover, 
it was in 1980 when NBC television produced and aired for the first time a special programme entitled "If Japan Can. Why Can't We?" (Salleh, Kasolang, \& Jaafar, 2012); hence, we chose 1980 as the starting point of our literature review.

\subsection{Journal Inclusion Criteria}

Much has been written on the topic of Japan's quality revolution. For this specific literature review, we used two of the main scientific databases - i.e. JSTOR and Emerald. Moreover, in order to restrict the articles relevant to our study, we formulated a number of inclusion and/ or exclusion criteria, which were as follows:

- Only peer-reviewed articles in English published between 1980 and 2018 (inclusive). Dissertations, conference papers, book reviews, etc. were not considered.

- Only peer-reviewed articles with the keywords "Japan" and "quality" included in their abstract. ${ }^{1}$

While the afore-mentioned two criteria could be set automatically through the advanced search engine options provided by both databases, we applied a number of additional criteria that had to be performed manually. Specifically, in order to synthesise and disseminate evidence across all "areas of Japan's quality movement, we had to opt for scientific outlets that go beyond the field of operations and/or quality management. Therefore, we included articles from the fields of a) Asian studies, b) business, c) cultural studies, d) development studies,

e) economics, f) history, g) management \& organisational behaviour, h) political science, i) science \& technology studies, and j) statistics. We used JSTOR's journal discipline categorisation. Each article was then screened appropriately and its content examined in detail to assure its focus of the study. The search was further enhanced by introducing the latest edition of the Australian Business Deans Council (ABDC) Journal Quality List (2019 edition) into the journal inclusion criteria. In other words, we included only peer-reviewed articles published in journals part of the ABDC Journal Quality List. The full details regarding the journal inclusion criteria are provided in Table 1.

\footnotetext{
${ }^{1}$ Some of the older articles did not have an Abstract section. In such cases, the database search engines would analyse the content of the Introduction section.
} 
Table 1: Journal Inclusion Criteria

\begin{tabular}{ll}
\hline Category & Criterion \\
\hline Research Type & (journal) articles \\
Peer Reviewed/Not Peer Reviewed & peer reviewed \\
Language & English \\
Year of Publication & 1980 - 2018 (incl.) \\
Length & at least five pages \\
Ranking & ABDC Journal Quality List \\
Methodology & qualitative and quantitative \\
Keywords & Japan; quality \\
Search Field & abstract \\
\hline
\end{tabular}

The results of the systematic literature review are presented in Table 2 below. Overall, based on the journal inclusion criteria, 59 articles in total - 19 from JSTOR and 40 from Emerald - were deemed relevant. The main reason behind this discrepancy - i.e. the difference between the number of relevant articles extracted from each of the two database - can be largely explained by the fact that Emerald contains a larger number of journals that are exclusively focussed on operations/ quality management (e.g. International Journal of Quality and Reliability Management, The TQM Journal). Besides the JSTOR and Emerald articles, we included another seven articles, which were extracted from one of the author's PhD thesis that investigated the quality movement in Japan and Table 2: Results based on the Journal Inclusion Criteria

\begin{tabular}{lcccc}
\hline & \multicolumn{4}{c}{ Database } \\
\cline { 2 - 5 } & \multicolumn{2}{c}{ JSTOR } & \multicolumn{2}{c}{ Emerald } \\
\hline Search Results & \multicolumn{2}{c}{295} & \multicolumn{2}{c}{195} \\
(Total Number of Articles*) $_{\text {Journal Inclusion Criteria }}$ & Removed & Remaining & Removed & Remaining \\
Field-related Articles & 246 & 49 & 99 & 96 \\
Research topic-related Articles & 19 & 30 & 32 & 64 \\
ABDC Journal List & 11 & 19 & 16 & 48 \\
Manuscript Length & 0 & 19 & 8 & 40 \\
\hline Articles included in the manuscript & $\mathbf{1 9}$ & & $\mathbf{4 0}$ \\
\hline
\end{tabular}

Note: * Peer-reviewed articles with the keywords Japan and quality included in the abstract. 
has served as the basis for this manuscript. These topic-relevant articles come from some of the top-tier journals in the field of operations/quality and general management, and are also part of the ABDC Journal Quality list (i.e. International Journal of Production Economics, International Statistical Review, Long Range Planning, Organizational Dynamics, and Technovation).

Finally, based on our systematic literature review (while not exhaustive), a number of emerging themes critical to Japan's quality revolution were put to the fore (for details, refer to Table 3 below). Each of these themes is given meaningful consideration in providing a detailed account of the quality movement in Japan from the Meiji period until the present - i.e. section 3 of this manuscript. The emerging themes are then analysed further in Section 4.

Table 3: Emerging Themes based on the Literature Review

\begin{tabular}{ll}
\hline Theme & Example \\
\hline $\begin{array}{l}\text { Government Support/ } \\
\text { Interventions }\end{array}$ & $\begin{array}{l}\text { the Japanese government usually works to help } \\
\text { Japanese firms and attempts to help to resolve } \\
\text { conflicts } \\
\text { they (the Japanese) have an entirely different } \\
\text { culture from the rest of the world }\end{array}$ \\
Extraordinary Circumstance & $\begin{array}{l}\text { the post-war occupation's civil administration } \\
\text { helped modernise manufacturing through } \\
\text { product standardisation, quality control, and } \\
\text { professional education }\end{array}$ \\
\hline
\end{tabular}

\section{Quality Movement in Japan from the Meiji Period until the Present Day}

\subsection{Quality Movement before and during the Meiji Era (1868-1912)}

\subsubsection{Preconditions for Industrialisation and the End of Isolation}

Given that Japan was under seclusion for over two hundred years known as the Edo period (1603-1868), not much is known about the country's manufacturing and quality movement prior to the beginning of the twentieth century. Broadly speaking, even in the nineteenth century, Japan was considered a weak, agricultural nation with low technological advancement (Trevor, 1986). At the same time, certain streams of the literature (e.g. Mahon \& Dyck, 1982; Ohno, 2006) claimed that under the international isolation (the Edo period), the country's 
trade, finance and industry grew, and importantly, a number of preconditions for industrial development and modernisation were met. To name a few: (1) political stability, (2) development of transportation, (3) rise of pre-modern manufacturing (i.e. food processing), and (4) high level of education. Mahon and Dyck (1982) contended that Japan's ideal of quality, in fact, dates all the way back to the Tokugawa period. It was, however, in 1853, when the (actual) industrialisation kicked off (Ohno, 2006; Johnson \& Chuang, 2010). As Japan's international isolation curtain was finally demolished, the country began to open up to the rest of the world; few years later, a new government - the Meiji Government came into power and restored the emperor (Ohno, 2006).

Following the military humiliation by the West (Creelman, 1993), the (new) Meiji government had two major goals: (1) to catch up technologically with the West which was much more advanced than expected, and (2) to create modern industries. Given these aspirations, Japan concluded the first commercial treaties with the West (e.g. Germany, Italy); accommodated foreign diplomats and merchants thereby introducing new ideas, technology, and systems (e.g. production methods); and also hired a large number of foreign advisors to assist the country. Thanks to these and other initiatives (e.g. high-level official delegations sent to the US and Europe), in less than two decades, Japan was able to introduce new metric weights and measures, a new monetary system, and banking (Ohno, 2006; Johnson \& Chuang, 2010; Lee, 2014). Parallel to that, the government began to (strongly) support the emerging of the private sector and the creation of domestic industries that would drive foreign rivals away. This policy was called yunyu boatsu (import substitution). Education and training was yet another priority of the Meiji government; the first institute of technology - Kobu Daigakko, and a number of technical high schools were founded across the country to promote midlevel engineers. Moreover, Japan's finest students were sent to study at the best institutions of higher education in Europe and America with financial support from the Japanese government (Ohno, 2006).

\subsubsection{National Criticism, Production Approaches and (Product) Quality}

In the following years, Japan formed its first parliamentary government ever, won a war against China and Russia, and colonised Taiwan and Korea. Despite the country's notable progress, critics of Japan's industrialisation and modernisation approach were not rare. Some of the Japanese elite claimed that the country's modernisation was superficial, and unlike the development in the West, which was defined 
as endogenous (emerging naturally from within), Japan's development was the exact opposite - exogenous (forced to take certain forms due to external influences) (Ohno, 2006). These assertions were not farfetched: according to the literature, during Meiji, many European and American machines were copy-produced by the Japanese through reverse engineering. Concurrently, however, the Japanese approach was rather unique. Specifically, while the "catching up with the West" policy through absorbing foreign technologies and methods was (largely) based on tight cooperation (e.g. joint ventures) with Europe and the US, it was common for the Japanese to dissolve relationships with Western partners shortly after absorbing new technologies. Most importantly, the Japanese would often (consciously) focus on preserving their traditional production approaches, and, thus, at times, they would modify imported technologies (this phenomenon is described as "hybrid technology" by Odaka - see Ohno, 2006).

Overall, during the Meiji era, Japanese machines were of low quality and exports were extremely limited - "Made in Japan" meant low price and quality (Mahon \& Dyck, 1982; Ohno, 2006). As Lee (2014) notes, very few Japanese businesses were technologically competitive with the West. And although the Meiji period was characterised by light industrialisation (with the machinery industry being still underdeveloped), a number of medium-sized private companies in the field of shipbuilding and railroad construction were inaugurated. Further, unlike the finest graduates in the West who would usually chose careers in economics and law, their Japanese counterparts took notable interest in engineering. Hence, later on Japan was described as a country of manufacturing things - monozukuri. Also, specific for this period was the inter-firm migration of engineers, which, in turn, facilitated technology transfer(s) and absorption. At the time, Japanese managers were described as more of generalists than specialists, and job-hopping was very common. Also, the Japanese workforce was characterised by severe lack of discipline. Finally, during Meiji, the first quality standards on silk were imposed (Ohno, 2006).

\subsection{Quality Movement from the Start of the 20th Century until the End of WWII}

\subsubsection{Pre- and Post-WWI Period}

At the beginning of the twentieth century, Japanese products were (still) of inferior quality and relied on imports of high-quality machines and 
industrial materials (Mahon \& Dyck, 1982; Trevor, 1986; MacDonald, 1987; Ohno, 2006). Nevertheless, as WWI erupted in 1914 and European goods became unavailable, Japan experienced a sharp rise in export demand: Japanese products including cotton and silk gained (short-term) popularity in overseas markets such as the US, which was experiencing an economic boom at the time. The favourable circumstances for economic growth brought by WWI had, however, a negative effect on the quality movement in the country, we argue. The short-term economic boom yielded by foreign demand for Japanese products allowed for the haphazard, massive expansion of businesses of inefficient producers who built substantial wealth at the time. These newly riche were called narikin (Ohno, 2006).

During the early 1920s, when the economic bubble created by WWI exploded, the lack of competitiveness and overcapacity of the Japanese industries resurfaced. Around the same time, the Americans, under the patronage of Dr. Walter Shewhart, took manufacturing quality to the next level - statistical techniques were employed in manufacturing for the first time (Gehani, 1993; Adams \& Miranti, 2008). This marked the rise of a new discipline - Statistical Quality Control (SQC), which later on became the cornerstone of Japan's quality movement (Robinson \& Shroeder, 1993; De Miranda, 2003; Fisher, 2009). In the consequent years, the economy slowed down, yet the manufacturing industries were still growing, especially the heavy and chemical ones. Also, during the early 1900s, a number of Americans travelled to Japan and made significant contributions to industrial technology; Charles Francis - Toyoda Automatic Loom Works, William Gorham - Kubota Steel Company. In fact, by the early 1930s, Japan was already producing most machinery domestically (Ohno, 2006). Meanwhile, Japanese product quality experienced slight improvement(s) as major Japanese companies such as Nissan, NEC, and Mitsubishi tied up with American and European counterparts in the form of joint ventures and technical cooperations. Further, due to the financial crisis of 1927, which was merely a banking crisis, most of the narikin - inefficient producers - had to close down their businesses as the financial supply to small and medium enterprises (SMEs) decreased substantially. Unfortunately, between 1930 and 1932, an even worse economic crisis - The Great Depression - hit Japan. Most of the unprofitable firms and banks that survived the 1927 banking crisis went bankrupt during this period (Ohno, 2006). These events must have had some positive effect(s) on the quality movement, we argue; yet, we also admit the crisis' negative effect(s) in the sense that due to deflation 
and falling prices, manufactures rushed to increase production (which is usually at the expense of quality) in order to maintain their earnings.

\subsubsection{Pre-and WWII Period - Militarization of the Economy}

By the mid-1930s, following changes in political power and turnaround policies, the Japanese economy began to recover. During this period, however, the military started overtaking Japanese politics and shortly after the Manchuria (North-eastern China) incident, Japan withdrew from the League of Nations, which left the country in international isolation. In 1937, the Japan-China War erupted, and the capitalist oriented economy (until then) was transformed for war execution. Even though most Japanese enterprises remained in the hands of the private sector, they were tightly regulated to contribute to the wartime efforts. Military production was maximised at the expense of light industries (e.g. textile industry - Japan's leading industry at the time). The Japanese economy became a planned one and remained so until the beginning of the Korean War (1950) (Ohno, 2006). Given these circumstances, as well as the controversial economic policies and the chaos created by the strong desires for military power, (product) quality was far from a priority in the period 1937-1945. Also, imperative for the period between the two wars is a little known fact about the (consequent) rise of Japan as a world leader in quality manufacturing. Specifically, even though product quality in Japan before WWII was considered of little importance (e.g. Ohno, 2006; Fisher, 2009), the Japanese were well-aware of a certain system of management - the Bata System of Management - that would (later on) become the basis of today's QM. According to Fisher (2009), the Bata System of Management developed by Tomas Bata (a Czech industrialist and owner of one of the first international companies) was studied by the Japanese well before WWII. In fact, Bata himself visited Japan in 1937 and predicted the industrial rise of the "Country of the Rising Sun".

\subsection{Quality Movement in the Period 1945-1949}

In August of 1945, Japan surrendered and came out of WWII as one of the most severely affected major powers. Besides the lack of natural resources - Japan's main obstacle to economic growth and military success in the past (Tattersall, 1989), in the first years of post-war recovery, the country suffered from scarcity of labour, and devastated 
industry and infrastructure (Leitner, 1999; Ohno, 2006). More than 80 per cent of the industrial facilities were destroyed, and production was at 10 per cent of the pre-war level (Robinson \& Schroeder, 1993). With this in mind, what puzzles most experts on economic development is how Japan transformed into a nation with the world's second highest living standards.

\subsubsection{A Special Situation and a Special Need}

Based on memoirs of General Douglas MacArthur - the Supreme Commander of the Allied Forces (SCAP), it was the need to communicate a series of edicts to the Japanese people that prompted the quality movement (Robinson \& Schroeder, 1993; Fisher, 2009). Specifically, in the beginning of the reconstruction process, there were no widely circulated newspapers, travelling around the country was difficult, and the telephone system was severely damaged - the wartime air raids destroyed half of Japan's telephones at the time (Adams \& Miranti, 2008). There was also no radio broadcast system (Fisher, 2009). Moreover, the manufacturing industry was in a knock-down state - almost all producers of communications equipment were out of business and product quality was dreadful. Since the Allied Forces were extremely concerned with public peace and order in Japan, quality control came back to mind and improving quality of communications equipment became a top priority (Adams \& Miranti, 2008). Moreover, there were those in Washington who feared that a stagnating Japanese economy would force Japan to seek to restore ties with Russia and China thus being drawn into the communist orbit (Leitner, 1999).

In compliance with the new rules and regulations issued by the Occupied Forces, all Japanese industrial cartels (zaibatsu) were abolished, their managers removed from their positions and replaced by individuals from the ranks of operating managers (Leitner, 1999; De Miranda, 2003; Kusago, 2007). By then, the Americans had already developed the so-called Training Within Industry (TWI) programme, which they believed would be ideally suited to train the newly appointed managers (Robinson \& Schroeder, 1993). Moreover, in this extremely hostile environment that was also characterised by lack of qualified labour, the pursuit of quality began. Here, it is important to note that many of the characteristics of post-WWII Japan including heavy and chemical industrialisation drive, subcontracting in manufacturing, and lifetime employment were already adopted in the 
war period 1937-1945 (Ohno, 2006). Thus, even though, the Occupied Forces introduced a number of new concepts that later on proved pivotal to Japan's post-war recovery, many of those concepts were based on wartime Japanese policies and systems.

\subsubsection{The Human Factor}

During mid-1946, the quality movement was still impeded by primitive and unreliable production facilities with extremely deplorable working conditions and intolerable material wastes (Adams \& Miranti, 2008). Under these circumstances, upgrading quality was extremely difficult to achieve; thus, in March 1946, the Allied Forces (by order of General MacArthur) summoned one of the best American radio engineers at the time - Sarasohn - whose mission was to help the Japanese with product quality improvement. Workplace cleanness, scheduled machine maintenance, on time work-flow, effective job training, and realistic quality standards became among the main priorities of the Japanese personnel. Yet, what Sarasohn sought the most was expressed in the form of progressive management, which combined commitment, a personal sense of ownership, and feedback across all organisational levels: notions that were in direct contrast of the pre-war Japanese industry. This was a focal point in the post-war reconstruction of Japan. As Adams and Miranti (2008) note, thanks to the civilian and military personnel who served in the CCS (Civil Communications Section) - special staff of SCAP, Japan was offered a solid institutional foundation that Japanese managers adopted to local economic and cultural circumstances.

During the same period, aside from the Allied Forces, two Japanese young officials - Saburo Okita and Yonosuke Goto - were also working hard at the forefront for economic recovery (Ohno, 2006). Via a privately financed study group, the two men drafted a report entitled "The Basic Problems of Japan's Economic Reconstruction" that served as an excellent start for the post-war recovery, and has been considered a benchmark for Japan's development policy advice since then (Ohno, 2006). Most importantly, upon careful analyses of the "Basic Problems" report, we register specific concerns about Japanese quality manufacturing: “The principle role in Japan's economic reconstruction will have to be played by manufacturing ... as Japanese heavy industries are certain to be subjected to international competition in the future on the one hand, and because the benefit of adequate governmental protection as experienced in the past will become difficult to obtain on 
the other hand, they will have to cultivate-through the rationalisation of management and the elevation of technological levels - the ability to withstand the competition from foreign goods in terms of production costs as well" (Ohno, 2006 - p.111-112, excerpts of the report).

Finally, even though the Japanese economy started to rebound thanks to the so-called priority production system policy, which favoured a number of industries, inflation (which was very high during the first few years of the post-war period) continued to persist. Thus, in order to further accelerate the reconstruction of Japan and the improvement of quality, besides Sarasohn who was already involved in rebuilding the Japanese communications system, the US dispatched two more prominent engineers to Japan - Deming and Protzman. Dr. Deming's initial focus was on statistical affairs, whereas Protzman's focus was on production management (Gehani, 1993).

\subsubsection{First Product Certifications and Management Qualifications}

Fisher (2009) noted that by 1948, the Japanese telecommunications system was already working with an acceptable degree of reliability. The Americans, however, did not stop there; two new concepts were introduced - (1) product quality certification and (2) management qualification. To adopt the first concept, a national electrical testing laboratory was established in Tokyo: all electronic, radio, telephone, telegraph and any related equipment became subject to a compulsory test before being offered to the public. Meanwhile, in 1945, the Japanese Standards Association (JSA) was founded and the Union of Japanese Scientists and Engineers (JUSE) was organised in 1946. Both associations became the main promoters of quality control in Japan in the following years (Munchus III; 1983; De Miranda, 2003). Parallel to that, highly influential Ministry of International Trade and Industry (MITI) was established in 1949. MITI was to ascertain the imperfections of the market and to be an adviser to industry. A year earlier, the Labour Ministry Employment Problem Association (JEPA) which had to administer the TWI programmes and to disseminate them throughout both industry and government (Robinson \& Schroeder, 1993).

As to the concept of management qualification, a number of intensive management-related courses were offered. These courses focussed on addressing and tackling the pervasive influence of feudalism on Japanese managers. To do so, senior Japanese executives were required to attend these courses and no substitutes were allowed. Also, to increase 
the success of the courses, Japanese government officials and university professors were invited, too. Management seminars were yet another tool that targeted quality improvement. According to Fisher (2009) Quality Control was allocated more time than any other topic, and the ultimate purpose of the first rounds of seminars was to clearly identify the importance of quality over any other aspects of operations management.

\subsection{Quality Movement in the Period 1950-1972}

\subsubsection{Korean War (1950-1953)}

1949 was a year of a worldwide economic recession that was strongly felt in Japan (Ohno, 2006). The outbreak of the Korean War, however, became (somehow) a basis for Japan's post-war economic growth. With US' involvement in the war, the American army had to turn to the Japanese for the provision of all kinds of military supplies; Japan was the closest and thus, the fastest available supplier. The Korean War was a godsend to the Japanese economy (Leitner, 1999; De Miranda, 2003). For instance, just in August 1950, the US signed contracts with Japanese suppliers for the procurement of goods and services worth over USD60 million. And even though the war shifted the priorities of the Occupied Forces, the success in the field of quality that was achieved by Sarasohn in the first years of the post-war period had to be continued. The Americans knew that winning the war required the usage of products of superior quality (Leitner, 1999).

\subsubsection{Deming and Other QM Gurus}

Given the war priorities, Dr. Deming was dispatched once again to Japan. Unlike previously, when he was studying Japan's demographics relative to food distribution and health statistics, this time, he was given the task to continue the works of Protzman and Sarasohn (Leitner, 1999; Fisher, 2009). Deming, thus, began teaching courses on the basic principles of Statistical Quality Control (SQC) (Gehani, 1993). As his teaching activities in Japan expanded over time, eventually, he became so influential to the quality movement in Japan that the first Japanese quality award - the Deming Prize - was named after him (Munchus III, 1983; Gehani, 1993; Khoo \& Tan, 2003). Around the same time, the initiative for the continuation of the CCS seminars was passed on to the Federation of Japanese Electrical Communications Industry Association. Further, with the arrival of Deming, a new quality improvement method was introduced - the Deming Cycle also known as the PDCA (Plan-Do-Check-Act) cycle. 
Besides Deming, other American QM gurus including Dr. Joseph Juran ("Quality Control Handbook"), Philip Crosby ("Zero Defect Movement"), and Dr. Armand V. Feigenbaum ("Total Quality Control") became (extremely) influential to Japan's quality revolution (Munchus III, 1983; Macdonald, 1984). Juran's teachings first came to Japan in 1954 and soon become an essential part of JUSE's educational program. In short, his ideas sought to elevate the level of quality management from the factory to the entire organisation. This was the beginning of what we now know today as Total Quality Management (TQM) (Dahlgaard \& DahlgaardPark, 2006). Feigenbaum's ideas, on the other hand, became the basis of the Japanese Total Quality Control (TQC) - an era that began in the early 1960s (De Miranda, 2003). Not long after Juran's series of lectures, the Japanese introduced the so-called quality control (QC) circles - a small group of individuals from different departments across the company who meet regularly to identify, analyse and solve quality-related problems (Sohal, 1998; Salleh et al., 2012). The invention of the QC circles has been argued as one of the pivotal add-ons to the quality movement - through introducing the QC circles, Japan added a human face to the SQC discipline (Chan, 1993; Creelman, 1993). By 1964, there were about one thousand QC circles registered in Japan (Munchus III, 1983).

The Korean War was not just an opportunity for Japanese firms to expand their operations, but also a chance for the newly appointed managers (following the dissolution of the zaibatsu) to prove that, regardless of their little experience, they could be as successful as their predecessors (Trevor, 1986; Kusago, 2007). Thus, driven by the great responsibility of rebuilding Japan, these hired professionals (just as their foreign counterparts - e.g. Sarasohn, Deming) had a direct impact on Japan's economic growth and product quality. Among the many Japanese who contributed a great deal to the post-war quality movement in Japan, we must mention Ichiro Ishikawa (the first chairman of Keidanren - the Federation of Economic Organisations, and founding chairman of JUSE), Dr. Kaoru Ishikawa (the originator of the fishbone diagram), Koji Kobayashi (the former chairman of the board and CEO of NEC, and the initiator of the small group activities as part of the zero defect movement), Taiichi Ohno (the vice-president of Toyota and the founder of the Toyota Production System - TPS).

\subsubsection{Government Policies - Protectionism and Domestic Financing}

Without natural resources (e.g. crude oil, silver), Japan had to import massive quantities of raw materials, and to pay for that, the country had 
to develop a key competitive advantage in order to boost its exports (Leitner, 1999; Ohno, 2006). Amid these circumstances, government policies for the protection and championing of the local industries played a vital role. Overall, the Japanese government managed to establish a long-lasting, win-win relationship with the private business, which was detrimental to the country's economic progress. For instance, in 1949, in order to boost its international competitiveness, the Japanese government signed a deal with the International Monetary Fund (IMF) (Kusago, 2007). The pursuit of economic growth was further supported by technological advancements. Up until the end of WWII, Japan was technologically behind Europe and the US in many fields; thus, during the 1950s, the government stressed the introduction of foreign technology. Through massive investments in research and development (R\&D) by both the government (e.g. through overborrowing - granting large amounts of low-interest, long-term loans) and private firms (Smith, 1993), the technological gap between Japan and the advanced nations such as the US was narrowed (Brouthers, Werner, \& Matulich, 2000; Kusago, 2007).

During the 1950-1972 period, fierce competition developed, especially within the automotive industry. Concurrently, the government started intervening less as trade barriers were lowered and FDI (foreign direct investment) policies were liberalised (Salleh et al., 2012). For instance, Audretsch and Yamawaki (1988) cited that up until the mid1960s, the Ministry of International Trade and Industry (MITI) was exerting a considerable influence over foreign technology purchases. This and other similar policies (e.g. R\&D expenditures subsidised by the government), however, were either lessened or abandoned in the later years. Nevertheless, the Japanese government continued to support the manufacturing sector. In 1958, the Japan Management Institute (JMI, which was renamed to Japan Quality Association in 1993) was established for the purpose of export inspection, and less than two years later, JMI moved from inspection to process certification. A year later, Toyota produced for the first time 100,000 cars in a year (Dahlgaard \& Dahlgaard-Park, 2006). Further, to compete more effectively with the US, the Japanese automakers were consolidated under the guidance of the Ministry of International Trade and Industry (MITI).

The exponential economic growth was also dependent on the labour force. Unfortunately, due to the disastrous impact of WWII on the labour supply, as well as the complete abolishment of the zaibatsu, the 
post-war labour market situation was extremely unfavourable (Chan, 1993; Leitner, 1999; Fisher, 2009). Amid these circumstances, Japan's new industrial leaders - the newly elected managers - had to be well-trained and well-motivated in order to be successful. Hence, training and education became the core of Japanese human resource management (HRM) as a number of Japanese government institutions and companies (e.g. Nippon Denso) paved the way for new standards in HR development. MITI and Nikkeiren (Japanese Federation of Employers' Associations), for instance, created jointly the Japan Industrial Training Association (JITA), which actively supported the disseminating of the TWI programs (Robinson \& Schroeder, 1993).

\subsubsection{Japan's Economic Miracle}

The 'Japanese miracle' started in 1950 (Deming, 1986; Kusago, 2007). Around that time, reconstruction of the economy was largely completed; however, Japan's per capita rate of consumption was only one sixth of the United States'. Yet, in just a few years, Japan managed to achieve an annual growth rate of 10 per cent, which continued throughout the 1960s (the 'Golden Sixties') and maintained its rate for approximately thirty years (the 'Japanese Economic Miracle'). Importantly, imperative to the economic growth was the introduction of the concept of quality control. As the broad QM literature asserts, Japan's rise to the rank of the second most economically developed nation in the world was largely due to a competitive model that centres on manufacturing quality products at a lower cost and price than those (products) produced by any other nation in the world (e.g. Macdonald, 1984; Chan, 1993).

By the mid-1950s, the living standards in Japan reached pre-war levels, and after more than a decade of prosperity, in 1968 - a century since the Meiji Restoration - Japan finally reached the national goal of catching up with the West. In 1970, Japan became the world's second largest economy after the US (Chan, 1993). The Japanese Society for Quality Control (JSQC) was established in the same year, and five years prior to that, the first Quality Control Symposium was organised in Japan. Around the same time, thanks to the Japan Management Association (JMA), which had already spread the concept of the Zero Defect movement as a nationwide initiative, the popularity of QC circles crossed national boundaries and was introduced in the US, and later on in China and South Korea. 


\subsection{Quality Movement in the period 1973-1989}

The high economic growth of the '50s and '60s ended in the early 1970s. The slowdown was not unique to Japan; in fact, the world fell into a recession due to a number of factors including the oil crises of 1973-74 and 1979-80. Yet, there were domestic factors that had a negative effect, too. Specifically, by the early 1970s, the Japanese economy had already matured, which meant that the country could no longer follow into the steps of the economic leaders: Japan had already become a leader. The challenge then was to reinvent the wheel, which is considerably more difficult than to follow in someone's steps (Ohno, 2006). Fortunately, the Japanese had already gained substantial experience in dealing with economic calamities (e.g. the post-war crisis).

\subsubsection{Another Special Situation and a Special Need}

At the outburst of the first oil crisis, Japan was 99.7 per cent dependent on foreign oil (Ohno, 2006); thus, the country had to reduce its energy consumption substantially and promote rationalisation of energyintensive industries. In line with this, the government introduced a setsuden (energy saving) national campaign; commercial signs on buildings and streets were discouraged; air conditioning systems were set to lower room temperature in the winter and higher in the summer (Ohno, 2006). The Japanese, however, were well-aware that more had to be done in terms of energy efficiency improvement and sustainable economic growth. So, how did Japan become the world's most energy efficient country in less than a decade?

Surprising or not, given the success of the post-WWII recovery period, quality control came once again back to mind. This time, however, the concept of quality broadened to deal with reliability, environmental management, and conservation of resources, which became a major concern after the first oil crisis (Berry \& Rondinell, 1998; Leitner, 1999). New quality tools and techniques were introduced, too. At NEC, for instance, the so-called policy of quality operations also known as New Seven Management Tools was initiated (Hamzah \& Ho, 1994). Following this policy, the role of management was clearly qualified for the first time and TQC was introduced in the services industry. During the same period, however, the literature argues that the consciousness about quality, especially among younger Japanese workers, diminished. Specifically, veterans in traditional Japanese firms reported that younger 
employees were not as conscientious about quality as they were a decade ago (in the 1960s). Thus, the 1980s were marked by substantial concerns among Japanese manufacturers about the availability of qualified supervisors (Ferdows et al., 1986). Education and training, however, continued to play a central role with over 90 per cent of the Japanese going to senior high schools and more than 30 per cent to colleges or universities in the 1980s (Hitomi, 1985). Broadly, the level of education in Japanese factories remained very high.

\subsubsection{New Trends in Japanese Management and Manufacturing}

Between 1973 and 1989, Japanese businesses started placing more importance on product innovation and product design, which used to be the Achilles heel of Japanese manufacturing industries (Ferdows et al., 1986; Garvin, 1986; Johnson \& Chuang, 2010). As Gehani (1993) notes, the Japanese started concentrating on mirhyoku-teki hinshitsu or admirable quality and market-creating quality products and services. Importantly, these innovations continued to revolve around productivity and/or quality (Herbig \& Palumbo, 1996), thanks to which, Japan's annual growth rate of productivity in manufacturing remained above nine (in comparison, the American productivity growth rate stood at 2.7) for almost two decades in a row (Lee \& Ebrahimpour, 1984). In 1979, for the first time, Japan achieved productivity levels that were higher than those in the US (Mahon \& Dyck, 1982). Further, multiple-product, small-batch manufacturing became a significant trait of the Japanese manufacturing excellence. Looking at the automotive industry, in 1969, Japan produced 85 models of cars, whereas in 1986, this number stood at 420 (Hitomi, 1992). Also, Toyota introduced the Just-In-Time concept in the early 1970s (Vuppalapati et al., 1995; Lim, Ahmed, \& Zairi, 1999).

Despite the global economic slowdown and future uncertainty, Japanese firms continued investing both domestically and abroad. Moreover, concerns with pollution control and labour-saving, for example, became a top priority in the '70s and '80s of the last century (Hamzah \& Ho, 1994). Moreover, investments in rationalisation measures (i.e. pollution control) reached an all-time high. For instance, Canon Corporation started applying life-cycle analysis to extend the life of its toner cartridges and make disposal more environmental friendly (Berry \& Rondinelli, 1998). Further, in the steel industry, almost 40 per cent of used electricity was provided from excess energy from within the plant. By the end of the 1970s, more than one hundred thousand 
quality circles were registered on a nation-wide basis (Munchus III, 1983; Ishikawa, 1985).

Besides product innovation, automation became another main driver of quality manufacturing improvement(s) among Japanese firms. Flexible manufacturing systems (FMS) were introduced for the first time, and computer-integrated manufacturing (CIM) became a major goal for many of the big manufacturing firms during this period. As Ferdows et al. (1986) noted, the Japanese manufacturers started seeking lower cost and flexibility. Thanks to the focus on automation, Japan's labour productivity in manufacturing continued increasing during the 1980s, and in 1989 productivity accounted for about ten times the productivity in 1960. Moreover, defect rates were reduced substantially, which boosted further the competitiveness of Japanese manufactures. For example, the defect rates in the automotive industry were between 0.35 and 2.6 per cent in the case of the US, compared to 0.01 per cent for parts made in Japan (Cusumano \& Takeishi, 1991). The Japanese plants were also much ahead of their counterparts in the UK, showing a 50 per cent superiority on defects per car (Oliver, Delbridge, \& Lowe, 1996). Following these developments, the Japanese machine tool industry increased its global market share to 25 per cent in 1989 from 15 per cent in 1980. Further, the Japanese vehicle exports rose from 18 per cent in 1969 to 52 per cent in 1982 (Trevor, 1986). Overall, the share of manufacturing industries in Gross National Product (GNP) reached 35 per cent in 1987; in 1957, the value stood at 16 per cent. Another reason behind these developments was diversification, which became a top priority for Japanese manufacturers in the ' $80 \mathrm{~s}$. Furthermore, Japan's international production picked up with ever more companies setting up overseas plants. In just one year (1986-1987), the Japanese manufacturers doubled their investments overseas reaching USD8 billion (Hitomi, 1992).

During the same period, Japanese management, which was recognised as excellent because of the great success of Japanese industries during the 1950s and 1960s, started undergoing modifications. For instance, due to financial constraints experienced by many Japanese firms, lifetime employment - one of the three pillars of Japanese HR management - was affected substantially as workers started being laid off earlier than their normal retirement age. Moreover, in line with criticism received from foreign countries and watchdogs regarding working hours in Japan, the Japanese government had to adopt new policies aimed at slashing the number of working hours per day 
(Hitomi, 1992). Nevertheless, absenteeism remained one of the lowest in the world in the 1970s (Hatvany \& Pucik, 1981; Oliver et al., 1996). Management training continued to be done within industry - TWI (Robinson \& Schroeder, 1993), and long-term business relationships (e.g. buyer-supplier) remained paramount (McMillan, 1990). As Ali and Al-Aali (1997) noted, regardless of the challenges, there was ample evidence that Japanese firms had the foresight and skills to compete in the future. Also, manufacturers continued to put efforts into QC circles (Ferdows et al., 1986). Finally, in the 1980s, a new term for quality control and management was cited for the first time - Total Quality Management (TQM) (Vuppalapati et al., 1995) also known as companywide quality control - CWQC (Zairi, 1994). Following the growing popularity of TQM, leadership commitment took central role in the pursuit of excellent product quality. Hence, top management leadership and strategic planning became the core of the quality movement in Japan (Ho, 1999; De Miranda, 2003; Dahlgaard \& Dahlgaard-Park, 2006; Phan, Abdallah, \& Matsui, 2011). Around the same time, 5-S (seiri-seitonseiso-seiketsu-shitsuke) started spreading across Asia through the Asian Productivity Organization (Ho, 2010).

\subsubsection{Government Support}

The post-war legacy of the Japanese government to support manufacturing continued with a number of organisations trying to boost productivity further. For example, the Japanese Ministry of International Trade and Industry (MITI) established an international project called Intelligent Manufacturing System (IMS), which aimed at integrating production facilities including robots and skillful human capital. At the same time, the government retained controlled of the industrial activity - in 1985, over 40 per cent of the industry was regulated by the government, with some sectors including mining, construction, and insurance being almost 100 per cent regulated (Hitomi, 1992). Besides the support from formal institutions, the Japanese government offered backing through other means including financial intervening. For instance, according to Smith (1993), between 1985 and 1989, the Finance Ministry deliberately inflated the property and securities market to offset the increasing value of the Japanese yen against the US dollar, which started hurting exports. This move sought to maintain the provision of bank funds for Japanese businesses. 


\subsection{Quality Movement in the Period 1990 - Present}

Japan's economic development in the 1990s and early 2000s was a far cry from most experts' predictions (Ohno, 2006). Specifically, the sentiments for continuous economic growth during the 1990s and 2000s (which were based on Japan's success in overcoming the two oil crises) did not materialise. Instead, a deflation and a recession along with intensified global competition came at the centre of Japan's economic policies (Fruin \& Nakamura, 1997; Ohno, 2006). These developments had a profound impact on the quality movement in Japan, we argue.

\subsubsection{Business Process Restructuring: Effects of the Economic Bubble Burst and Globalisation}

Due to the economic downturn, many Japanese companies suffered substantial financial losses in the 1990s. The product diversification that was pursued by large firms in the 1980s, in fact, had a negative effect on profitability following the economic bubble burst (Creelman, 1993; Pudelko \& Mendenhall, 2007). Given these economic hurdles, as well as the increased pace of globalisation, during the last three decades, Japanese manufactures have been placing substantial attention to and effort in restructuring their business processes. For example, in the 1990s, ISO 9000 certification became a requirement for exports to Europe; thus, Japanese industries were forced to obtain ISO certification in order to maintain and continue their expansion abroad. By the mid '90s, the Japan Quality Association (JQA) had already ISO-certified a few hundred firms in Japan, with the highest number of representatives being electronic companies.

Another important change that was observed during the 1990s relates to the strategic orientation of Japanese companies. Famous for their long-term orientation, which has often been at the expense of profits , Japanese companies, following the economic bubble burst, were forced to start thinking short-term as paying off debts became essential for survival (Munchus III, 1983; Zairi, 1994; Ali \& Al-Aali; 1997). Further, keiretsu (company networks) became less important and a substantial reduction in subsidiaries and suppliers was observed in the case of Hitachi, Sony, Nissan, and others alike (Pudelko \& Mendenhall, 2007). Industries such as mould-manufacturing - the base of all manufacturing - were severely affected by fierce competition from abroad. Thus, in December 1999, the Japan Organisation for Quality Innovation (JOQI) 
was established under the so-called "Hakone Declaration". This was followed by an era of TQM innovation.

\subsubsection{Concerns Arising from Foreign Competition}

Besides the shift in strategic orientation (more short-term focused), between 1990 and the 2010, Japanese industries underwent other significant changes in terms of the way they do business. In order to survive the new realities, Japan started pouring trillions into new capital investment for modernisation, quality improvement and cost reduction. Prior to the end of the century, Japan was already the leader in R\&D expenditures as a percentage of GNP among the industrialised nations (Herbig \& Palumbo, 1996). Moreover, with government support for local industries diminishing due to a concentration on domestic administrative reforms (Ohno, 2006) and rising competition in the region (e.g. China), since the 1990s, many Japanese companies started transferring their manufacturing capabilities abroad (e.g. Thailand) (Woodworth, 1991; Ohno, 2006). This move, however, has faced severe opposition and is currently prompting additional worries to the Japanese businesses. Specifically, today, many Japanese companies are afraid of high-tech manufacturing methods being copied by overseas competition (e.g. China and South Korea). For instance, Toshiba - Japan's biggest chipmaker - suffered in the past by sharing technological knowhow with South Korean chipmakers. Given these developments, the contemporary businesses policies of many Japanese manufacturers can be described as a balance between low-cost manufacturing abroad and high-tech development based on substantial R\&D investing within Japan.

Overall, since the 1990s, Japanese manufacturers' strategic thinking has been revolving around process control, supplier quality involvement, innovation, small group problem solving, and customer involvement, with only the latter one scoring higher in the new century (Sohal, 1998; Phan et al., 2011). This trend is not surprising, since customers have become more sophisticated and demanding. Hence, cheap labour has not been the only motive for Japanese companies moving abroad; Japanese manufactures have also realised that building plants close to their markets reduces production times, distribution costs, and currency losses. By the later '90s, Japanese plants had already achieved an impressive rate of on-time delivery to their clientele (Oliver et al., 1996). On top of that, by being closer to the customer, it has been easier for companies to meet regional needs. Relevant to the afore- 
mentioned statement examples include Toyota and Honda - the two largest Japanese automobile producers. Broadly, in recent years, the Japanese manufacturers are placing even more importance on employee suggestion, information feedback, and group problem solving. In essence, what has become a genuine trait of Japanese manufacturers in this century can be summarised as cross-functional communication and information sharing (e.g. with suppliers) (Liker, Kamath, \& Wasti, 1998; Phan et al., 2011).

\subsubsection{Influence of Labour Policies and HRM Restructuring on QM}

On the HR management side, in line with aging population, an increasing use of part-time and contract labour, especially in the case of low-level jobs has been observed since the 1990s (Sohal, 1998; Chan, 1993; Kusago, 2007). This trend has somewhat hindered the education and training programs in the big manufacturing companies. Prior to the economic bubble burst, people were usually put ahead of profit (Lee \& Ebrahimpour, 1984). Overall, traditional Japanese management characteristics and lifetime employment in particular have continued restructuring (Fruin \& Nakamura, 1997). Broadly, Japanese companies have begun borrowing (more often than ever before) western practices such as pay-per-performance and more frequent usage of non-regular employees (Westbrook, 1995). These shifts in labour policy are becoming a major challenge for Japanese manufacturers whose HRM strategies (traditionally) revolved around lifetime employment, we argue.

\subsubsection{Resilience of Japanese Manufacturing}

Even though many Japanese companies have been undergoing restructuring due to financial and other difficulties (e.g. contracting domestic market and increasing competition from abroad) since the 1990s, today's well-managed Japanese organisations continue to hold their competitive powers akin to the quality revolution era - i.e. quality, cost, and delivery (QCD) (Sohal, 1998). For instance, Dahlgaard, Kristensen, Kanji, Juhl and Sohal (1998) showed that hundred per cent of the Japanese companies reported in their study had developed and implemented a quality policy document. Moreover, Zhao et al. (1995) argued that among the industrial leaders - Japan, the US, and Germany, the Country of the Rising Sun had the highest percentage of companies (70 per cent) using quality information to evaluate business performance monthly. Overall, 
regardless of the economic downturn, as well as the HRM modifications in terms of lifetime employment and seniority-based wages among other issues that Japanese management started experiencing since the late 1980s, Japan has remained interested in factory operation(s) and product perfection (Sohal, 1998; Phan et al., 2011). Specifically, Japanese management practices such as TQM, JIT, and TPM (total productive maintenance), which were advanced as best practices in the 1990s, have continued to play an important role in organisational survival and prosperity. Fruin and Nakamura (1997) argued that the prolonged economic recession has forced the Japanese manufacturers to take a fresher look at top-down approaches (e.g. TPM) that are not (necessarily) new, but have been avoided at the expense of bottom-up approaches (e.g. TQM) not until long ago. On the other hand, automation has continued to draw further attention among manufacturers. Specifically, the dramatic technological and R\&D advances in robotics from the 1980s onwards have already earned Japan the title of the 'robotic kingdom'. Moreover, during the 1990s and beyond, the Japanese manufacturers kept on allocating time and effort to shop floor activities such as small group activities (e.g. QC circles). Dahlgaard et al. (1998) reported that by the start of the new century around 95 per cent of the Japanese firms were using QC circles. Similarly, following the trends in the '70s and ' 80 s of the last century, the Japanese have continued advancing within the product areas that needed improvement such as energy efficiency, product design, etc. Regardless of the fierce competition from China, South Korea and Taiwan, Japanese manufacturers have not changed their strategic focus on quality. Overall, they have remained very specific and continue to manufacture high-quality products at a very low cost (Phan et al., 2011; Zhang \& Xia, 2013).

\section{Discussion}

This paper has a tri-fold purpose. First, we wanted to stress the importance of product quality upgrading as a driver of economic growth through analysing Japan's quality movement from the Meiji period until the present day. Second, we also sought to add to the existing QM literature by filling a substantial gap regarding the influence of the external environment (e.g. political factors, social factors) on the success/failure in quality upgrading. Third, we wanted to explore the current strategic weapons of competitiveness of Japanese businesses, and more precisely to verify whether quality management $(\mathrm{QM})$ is still 
being pursued as a competitive advantage. Given these goals, we discuss our findings below.

\subsection{Quality Upgrading - A Conscious Choice in Pursuing Economic Growth}

Less than a century ago, 'Made in Japan' was synonymous with low price and poor quality (e.g. Trevor, 1986; Chan, 1993; Gehani, 1993; Goldman, 2005; Ohno, 2006). In the late '30s and early '40s of the twentieth century, product quality in Japan was far from being a priority (De Miranda, 2003). The end of World War II (WWII), however (as our synthesis showed), marked a turning point in the development of the Japanese economy. Driven by patriotism and desire for change for the better, the Japanese focussed their efforts on developing Japan's ability to withstand foreign competition. The core of their approach required the immediate rationalisation of management and elevation of technology, which was ultimately to yield the manufacturing of high quality products at low cost (Mahon \& Dyck, 1982; Smith, 1993; Hamzah \& Ho, 1994; Ohno, 2006). The Japanese knew that manufacturing is of imperative importance in creating the wealth of a nation (Reitsperger \& Daniel, 1990; Hitomi, 1992; Salleh et al., 2012). Hence, with some help from the Americans, almost twenty-five years later, in 1970, "Made in Japan" became the world standard for quality, and Japan became the world's second largest economy after the US (Garvin, 1986; Brouthers et al., 2000). Most importantly, however, one of the decisive reasons for Japan's Economic Miracle (and especially, the 10\% economic growth between the 1950s and the 1960s) was the diffusion of quality control learned from the Americans (Macdonald, 1984; Gehani, 1993). The quality focus trend continued until the end of the twentieth century, and while there have been shifts in the competitive environment in the last two decades (e.g. focus on innovation), our synthesis showed that Japanese companies continue to value (product) quality as a driver of economic growth. Certainly, the Japanese economic growth today is far from its former glory - visualising Japan's Economic Miracle, yet the current economic environment is a result of a complex mix of internal and external factors that go beyond the scope of QM, we argue.

\subsection{Quality Upgrading and the External Environment}

Japan's unprecedented success in quality manufacturing also known as the quality revolution is not a subject to debate; as our literature 
review showed, less than a century ago, "Made in Japan" meant cheap and poorly made product (e.g. Trevor, 1986; Gehani, 1993; Petersen, 1993). Moreover, the end of WWII left Japan in a political, economic, and social knockdown. Today, however, Japan is the world leader in quality manufacturing. Given this, the following perennial questions resurfaces - how did the Japanese manage to become the world leader in quality manufacturing? Through our systematic literature review, we identified a number of external factors (see Figure 1) that we discuss below. Importantly, even though the emerging themes mentioned in the Methodology section were three in total; we have decided to present a fourth construct here, which often comes under the so-called political domain.

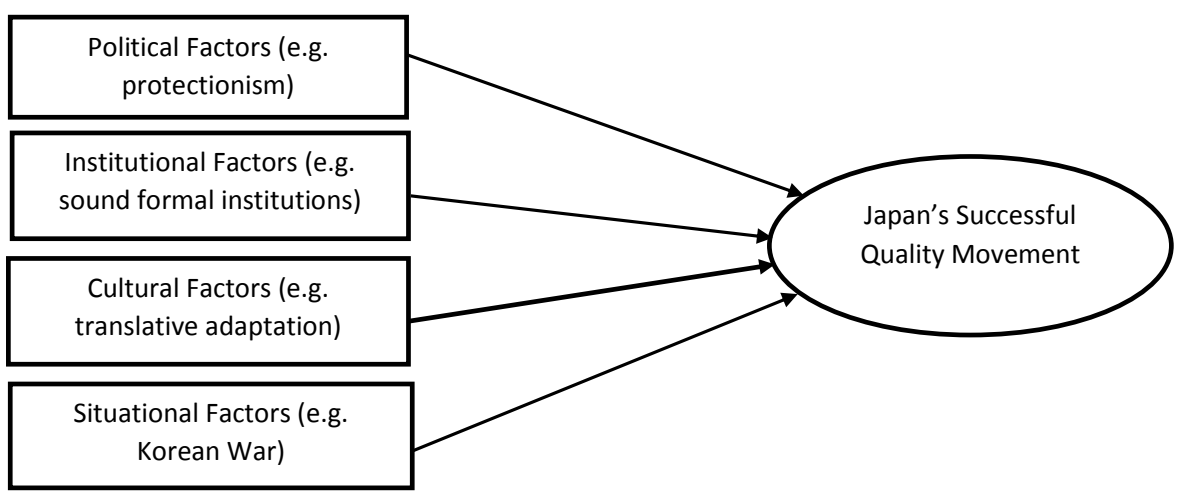

Figure 1: Quality Movement and the External Environment ${ }^{2}$

\subsubsection{Political Factors (Governance)}

\section{Government Policy - "Import Substitution"}

Our study showed that since early days, the Japanese approach to industrialisation and modernisation has been focussed on absorbing foreign knowledge and technologies while adopting them to the Japanese context, and eventually perfecting them (e.g. Herbig \& Palumbo, 1996; De Miranda, 2003; Johnson \& Chuang, 2010). This philosophy is clearly reflected in the yunyu boatsu (import substitution) policy from the Meiji

\footnotetext{
${ }^{2}$ We realise that the so-called institutional factors can be included in the political ones; however, by separating them, we seek to emphasise probably the most severely ignored reason behind Japan's success in quality manufacturing, which involves the authors' latest research project.
} 
period (Ohno, 2006). Broadly, Japan understood modernisation not as the mere acceptance of the Western civilization, but as an opportunity to carefully select those Western traits that would prove beneficial to the Japanese realities (this is called 'translative adaptation' - a term coincided by Maegawa; see Ohno, 2006). As our synthesis revealed, even in cases when Western technology was much more advanced, the Japanese (consciously) focussed on preserving their traditional methods; hence, at times, they would modify imported technologies. This philosophy along with the government policies, we argue, is what made Japan so successful in improving product quality and creating new approaches such as Total Quality Management (TQM) that later on became the cornerstone of the global quality movement - approaches that were based on American doctrines, but interpreted in a Japanese fashion (De Miranda, 2003). Wakon yosai (Japanese spirit; Western learning) - a slogan used during the Meiji period - is one of the keys to Japan's competitive capabilities, we argue. It is also important to stipulate that the import substitution policy has a cultural aspect to it (from the perspective of translative adaptation) which we discuss in section 4.2.3. Essentially, government guidance is being argued as one of the fourteen unique features possessed by the Japanese society (Fah, 1988).

\section{Government Policy - Industry Support and Protectionism}

According to our synthesis, government support played a crucial role in Japan's quality movement success (e.g. Lee \& Ebrahimpour, 1984; Ali \& Al-Aali, 1997; De Miranda, 2003; Audretsch \& Yamawaki, 2014). Broadly speaking, the Japanese government had the tendency to encourage the development of more advanced sectors of the economy through political and administrative means (Herbig \& Palumbo, 1996). As Ohno (2006) asserted, since the Edo period, the Japanese authorities took responsibility and great initiative to support the country's manufacturing industries. This policy somewhat changed during the Meiji era, but WWII provided a good "excuse" for the shift back to the relational and interventionist system. Japan's post-war economic development was characterised by a government-induced market economy, and more precisely, it was the government that decided in what industries to invest (Mahon \& Dyck, 1982; Herbig \& Palumbo, 1996; Adams \& Miranti, 2008). For instance, besides the policies for the protection and championing of local industries, the government also managed to establish long-lasting, win-win relationships with the private sector (Lee \& Ebrahimpour, 1984). These initiatives played a pivotal role in the pursuit of heavy 
industrialisation and economic growth (Ohno, 2006). Even after the 1970s (when Japan become the world's second largest economy and the government started to intervene less), the Japanese ministries remained strongly involved in supporting the manufacturing sector. For instance, during the 1980s, over 40 per cent of the industry was regulated by the government, with some sectors including mining, construction, and insurance being almost 100 per cent regulated (Hitomi, 1992).

\section{Government Policy - Investment(s) in Education}

Japan's success in quality manufacturing would not have been possible without the presence of an advanced, tailor-made educational system, we argue. As we showed, Japan's finest graduates, unlike their Western counterparts, took and still take notable interest in engineering. This, in fact, is how Japan was able to become a country of manufacturing things (Ohno, 2006). Moreover, since before the Meiji Era, the Japanese government had been continuously investing in education (Johnson \& Chuang, 2010), thereby creating world class universities (e.g. Tokyo University, Tohoku University), where individuals gain valuable knowledge and skills necessary to lead the "Country of the Rising Sun" toward continuous economic growth and social prosperity. Mahon and Dyck (1982), for instance, noted that by 1900, more Japanese could read than Western Europeans. We must also note the importance of training within industry. As we showed, the so-called TWI (Training Within Industry) programmes, which were designed in the US and later on brought to Japan, were vital to the country's success in quality manufacturing (Robinson and Schroeder, 1993). Moreover, when statistical quality control techniques were first introduced in Japan, they were accompanied by decent educational and training programs that were well attended (Garvin, 1986). As Westbrook (1995) asserted, Japan's great manufacturing leap began with education by Deming, Juran and other QM gurus, and education has remained central to it. We, therefore, claim that the real secret behind Japan's success in quality manufacturing is its people.

\subsubsection{Institutional Factors}

\section{Strong Formal Institutions}

Our synthesis showed that many authors hinted on formal institutional support as a key factor in Japan's post-war manufacturing success (e.g. Fah, 1988; Robinson \& Schroeder, 1993; Westbrook, 1995; Herbig 
\& Palumbo, 1996; Audretsch \& Yamawaki, 2014). A myriad of organisations - national bodies, both governmental and non-governmental ones, supporting the quality movement in Japan - were established shortly after the end of WWII. To name a few: the Union of Japanese Scientists and Engineers (JUSE) - established in 1946 with the aim to promote quality control in Japan; Japan Management Institute (JMI, which was renamed to Japan Quality Association in 1993) established as the body responsible for export inspection and later on, for process certification. The list goes on: Japanese Industrial and Vocational Training Association (JIVTA) - the main training affiliate of the Nikkeiren (Japanese Federation of Employers' Associations); Japan Management Association (JMA) - the promoter of the Zero Defect movement; etc. These non-profit associations have produced many QM-related courses and delivered them to a great number of Japanese companies for over sixty years already (Westbrook, 1995). Most importantly, they have played a critical role in disseminating QMrelated knowledge across the country. Surprisingly, however, as Trevor (1986) asserted, the enormous influence of such bodies in promoting quality has remained unnoticed by most countries; even Britain - the mother of the Industrial Revolution - has overlooked the importance of formal institutions in diffusing the quality movement. While the critics of Britain's passiveness have their grounds, much worse is the case of many of the former communist states of Central and Eastern European that joined the European Union during the first decade of the new century (e.g. Bulgaria and Romania). Some of these countries do not even have a national quality award.

\subsubsection{Cultural Factors}

First, it is important to note that the debate on the relationship between the success of Japan's post-war quality movement and the Japanese culture remains unsettled. Specifically, certain experts on quality management (e.g. Macdonald, 1984; Trevor, 1986, Fah, 1988) believe that Japan's success in quality manufacturing has nothing to do with cultural factors. On the other hand, experts on cultural differences contribute the country's success to a strong blend of Japan's socio-cultural heritage and its management practices (e.g. Hill, 1989; Petersen, 1993; Goldman, 2005). In other words, the lack of such heritage and practices in the West has posed a major challenge for successful implementation of management philosophies such as TQM and Kaizen. As Goldman (2005, 
p. 217) asserted, "the Japanese culture had contributed to a level of quality heretofore not seen". Our synthesis supports (at least to some degree) the latter claims. While it is difficult to account for the entire spectrum of characteristics that make the Japanese culture unique, our synthesis showed evidence for three cultural traits that have had a significant influence on Japan's post-war quality movement success. These traits are discussed below.

\section{"Translative" Adaptation}

Japan today is very different from Japan in the past, but regardless of the external shocks that every nation absorbs throughout history, the Japanese have managed to retain their identity and today, the Japanese society can be described as a multi-layered one. Imperative to note is that the Japanese have become extremely skilful at absorbing a great number of conflicting elements and using them interchangeably depending on the situation (Hill, 1983; Ohno, 2006). Herbig and Palumbo (1996), for instance, asserted that the Japanese honour "first to apply", whereas the US honours "first to invent". Moreover, they have been very selective, especially in the case of Western business practices. As Pudelko and Mendenhall (2007) note, in both the Meiji period and the American occupation, in their learning from the outside world, the Japanese carefully considered the elements and circumstances of their culture and society. Importantly, research shows that the so-called translative approach continues to play a central role in the Japanese society and Japanese management per se even today. Specifically, following the economic bubble burst in the 1990s, the Anglo-Saxon management model to corporate governance was suggested to the Japanese as one of the tools for the third major transformation - the first two being during the Meiji period and the post-WWII years (Ohno, 2006). The Japanese, however, following centuries of experience, (again) carefully analysed the global economic situation and their inner capabilities, as well as cultural traits. Interviews with top management from leading Japanese companies such as Nippon Denso reveal that "they (Japanese managers) are well aware of management techniques which are frequently used by their American rivals, but largely reject them as being too short-term oriented" (Pudelko \& Mendenhall, 2007, p. 276).

\section{A Culture Dedicated to Continuous Improvement - Kaizen}

A certain stream of the literature argues that Japanese QM was built on and continues to revolve around the notion of continuous improve- 
ment also known as kaizen. Kaizen, however, is not just a tool, but a philosophy that has been practiced by the Japanese in and outside the workplace for centuries. Since the early days of the samurai and the cultivation of the Bushido philosophy (the way of the warrior), Japanese people, it seems, have always had a thirst for "kaizen". As Mahon and Dyck (1982) noted, the respect for learning (and improving) dates back to Tokugawa era and extends from the hereditary samurai elite down to the lowest class of merchants. This is clearly visible in the case of Japan's quality movement, which exemplifies a pursuit of continuous improvement. Our synthesis revealed substantial evidence for a culturebased specific strength of Japanese business to pursue operational effectiveness (e.g. Mahon \& Dyck, 1982; Kharbanda \& Stallworthy, 1991; Petersen, 1993; Pudelko \& Mendenhall, 2007). Some authors go even further by explaining the kaizen thirst with Japanese religion such as Zen Buddhism (e.g. Saha, 1992). Essentially, QM approaches such as TQM are embedded in the organisational cultures of most Japanese companies. Kidd (1995), for instance, stresses that the so-called kaizen suggestion system is simply a part of the normal world of work in Japan, whereas in the rest of the world (including countries with similar to Japan culture - i.e. Korea) this system had to be tied to well-defined financial incentives. Overall, we argue that the belief that there should be unending improvement is deeply ingrained in the Japanese mentality - something that is called achievement-oriented culture and linked it to the Japanese ethnicity.

\section{$\underline{\text { Individualism versus Collectivism }}$}

If many years ago, quality management (QM) was mainly about statistical quality control, today, the situation is very different. From TQC to TQM, the success of Japanese industries has been revolving around outstanding teamwork from the top management level all the way to the shop floor workers and factory cleaners (Hill, 1989; Garvin, 1986; Perman, 1989; Dahlgaard \& Dahlgaard-Park, 2006). This is to some degree a result of socio-cultural factors. For instance, Japanese culture is family-oriented, or in other words collective: the Japanese are an inherently cooperative people (McMillan, 1990; Ali \& Al-Aali, 1997; Leitner, 1999; Khoo \& Tan, 2003; Linner \& Bock, 2012). Specifically, Creelman (1993) argued that teamwork (which is considered essential to the success of modern QM approaches) is the product of the postWWII period when labour was scarce (we discuss this further under 
situational factors in section 4.2.4. Broadly, Japanese firms devote great attention and effort to structural factors that foster group work and collaboration, but what makes their efforts successful is the fact that group participation fits well with Japanese traditions (Deming, 1986; Kharbanda \& Stallworthy, 1991; Ho, 2010). Ishikawa (1985) noted that a main reason for the success of QC circles in Japan (in comparison with the US, for instance) is the alleviation of excessive individualism or me-ism. While this characteristic is common to almost all Asian nations, what makes the Japanese even more collectivistic is a number of historical events. This brings us to the next point - situational factors.

\subsubsection{Situational Factors}

Japan's post-war competitiveness and quality improvement success in particular has also been attributed to a degree of luck, visualising certain (past) events, which are argued to have played a crucial role in the quality movement (e.g. Creelman, 1993; De Miranda, 2003; Adams \& Miranti, 2008). While this and other similar explanations are difficult to prove, our synthesis did register a number of historical events that may, indeed, have been detrimental to Japan's success in quality manufacturing.

\section{WWII Aftermath}

To some degree, one of the (not to say the main) drivers behind the quality movement success in post-war Japan was a special situation and a special need as described by Sarasohn. Specifically, the US government had to rebuild the Japanese economy starting with improving the quality of communications equipment (the situation) in order to guarantee public peace (the need) (Adams \& Miranti, 2008; Fisher, 2009). As we noted previously, to the Allied Forces, providing good communications equipment for Japanese civilians was as important as providing food and shelter for them (Adams \& Miranti, 2008). The post-war success in quality upgrading was not only the result of the arrival and assistance of the Americans; the vision of the Japanese leaders for creating a modern and competitive manufacturing industry was also pivotal, and the dire situation in which Japan was at the time served as an even stronger motive for pursuing this vision. As Linner and Bock (2012) noted, Japan received very little economic support after WWII which is why it was required to find efficient ways to work with existing resources. 


\section{Korean War}

A number of articles cited that the start of the Korean War was a godsend to the Japanese as this event accelerated further the need for improvements in quality manufacturing (e.g. Creelman, 1993; Leitner, 1999; De Miranda, 2003). Simply, to win the war, the American army had to turn to the Japanese for the provision of military supplies and equipment - Japan was the closest and, thus, the fastest supplier of military goods. However, it was not just the manufacturing industry that profited from the outbreak of the Korean War. Through a number of massive deals for the procurement of military goods and services, the Japanese economy was given a substantial boost. Moreover, because of the start of the Korean War, Dr. Deming was dispatched once more to Japan, and it was then when he began to involve actively in Japan's post-war quality movement. It is, therefore, reasonable to raise the following question: a) would the Americans have accelerated the need for and their involvement in product quality improvement; and b) would Deming have returned to Japan, if a war on the Korean peninsula had not erupted?

\section{$\underline{\text { Oil Crises }}$}

While the above-mentioned two events and circumstances surrounding them may be considered somewhat unique to the Japanese context, the two oil crises in the '70s and the '80s were relevant to almost all world economies. Certainly, Japan's dependence on foreign oil was among the highest in the world - almost 100 per cent (see Ohno, 2006) and that, in turn, created another special situation and a special need (Vuppalapati et al., 1995; Leitner, 1999). Yet, there were other countries (at the time) in a similar position; however, they did not exploit the situation as effectively as the Japanese. And even though we know what measures the Japanese took to overcome the two oil crises (e.g. environmental management, and conservation of resources) and become the most energy efficient country in the world, why other economies in a similar state could not do the same is a question that, probably, would never be answered. Maybe, the experience that the Japanese gained in overcoming the postwar aftermath was detrimental to their consequent success in tackling challenges such as the oil crises, we contend.

\subsection{Quality Upgrading as a Contemporary Competitive Advantage}

Research works from the last two decades argue that the contemporary competitive landscape has shifted away from QM towards innovation 
(e.g. new product development) and other competitive domains that stress novelty. Moreover, in the new context of the twenty first century's manufacturing environment, the very core of Japan's economic system such as lifetime employment, seniority wages and subcontracting among others has been blamed for the economic downturn in the 1990s and 2000s. Our synthesis, however, showed that even beyond the 1990s, when economic experts and researchers began propagating that product quality was not an actual competitive advantage anymore, the Japanese have continued to explore quality management as a strategic weapon for competitiveness (Phan et al, 2011; Salleh et al., 2012). Most importantly, while many of the Japanese manufacturers have, without any doubt, undergone substantial restructuring since the late 1980s, we showed that regardless of the afore-mentioned shift(s) in the current competitive environment, quality has not lost its lustre and relevance in Japanese businesses. It - quality - is part of the Japanese style of thinking, and as such, it will not erode anytime soon, we contend.

\section{Conclusion and Further Research}

This is (probably) the first study of the path Japan travelled to become the world leader in quality manufacturing, analysing the country's quality movement from the Meiji Era until the present day, including the reasons behind its post-war manufacturing excellence. Importantly, through this synthesis, we emphasised the importance of product quality upgrading as a driver of economic growth. Specifically, we showed that the Japanese consciously focussed on quality manufacturing as they knew that it (manufacturing) is imperative for creating the wealth of a nation. Therefore, we contend that, from a practical standpoint, our synthesis provides a valuable lesson to the countries with a status of developing or underdeveloped economies (at present) in their pursuit of economic growth. This narrative is especially relevant because Japan's economic (prosperity) model through a focus on (product) quality has already been successfully emulated by several other countries including Singapore and Malaysia (e.g. Fah, 1988; Hamzah \& Ho, 1994; Salleh et al., 2012). Put differently, it is important for manufacturers from developing countries to understand their own quality management practices in comparison with those in Japan, which have the highest standards of manufacturing quality. This will help them to identify their current weaknesses.

This synthesis also cast some light on the external factors (e.g. political factors) that played a pivotal role in the rebuilding of Japan, 
in general, and the quality movement success, in particular. Even though some of these (external) factors may be unique to the Japanese context (e.g. the Korean War), our analysis revealed a number of factors (e.g. political factors) that may be considered universal in the sense that they can be cultivated by other countries (even today). In other words, what our synthesis argued is that, for instance, manufacturing excellence cannot be achieved without the conscious and active support of the government. This and the rest of the external factors identified through our systematic literature review are probably the most valuable contribution of our study, because we bring to the fore aspects of the quality movement in Japan that have either been completely dismissed or sporadically mentioned so far. Aside from very few exceptions (e.g. Malaysia), Ishikawa's argument from over thirty years ago that enhancing quality and productivity requires a multifaceted approach combining macro and micro factors (Ishikawa, 1985) has been ignored, it seems. Through this synthesis, however, we hope to reverse this trend. As Salleh et al. (2012) asserted, in order to have more worldclass companies, lots of initiatives on the government side must be implemented. Finally, our synthesis showed that, regardless of the shifts in the current competitive environment, quality has not lost its lustre and relevance in Japanese businesses. Given this, we argue that even though Japanese quality management is more than half a century old, this does not make it obsolete. On the contrary, it seems that because of its long history, Japanese quality management is built to endure, and by all means, we should not underestimate its contemporary economic power. This is the very reason why developing nations should not rush into the new era of technological innovations such as 3-D printing and Artificial Intelligence without recognising the importance of quality manufacturing as a driver of economic growth.

In conclusion, while research on Japan's quality movement has almost been exhausted, our study suggests a number of paths for future investigation. Specifically, the external factors for Japan's success in quality manufacturing must be given further consideration, we argue. For instance, consequent QM-related studies should look deeper into the impact of formal institutions and government support on quality upgrading. Also, given the dynamics of the current competitive environment, we contend that future research should further investigate why, regardless of the shifts in the competitive forces, quality continues to be explored as a competitive advantage by Japanese businesses. 


\section{References}

Adams, S.B., \& Miranti, P.J. (2008). Global knowledge transfer and telecommunications: The bell system in Japan, 1945-1952. Enterprise \& Society, 9(1), 96-124. http://dx.doi.org/10.1093/es/khm072

Ali, A.J., \& Al-Aali, A. (1997). A lack of creativity: Executives speak out. Management Research News, 20, 1-8. http://dx.doi.org/10.1108/eb028564

Audretsch, D.B., \& Yamawaki, H. (1988). R\&D rivalry, industrial policy, and USJapanese trade. The Review of Economics and Statistics, 70(3), 438-447. http:// dx.doi.org/10.2307/1926782

Berry, M.A., \& Rondinelli, D.A. (1998). Proactive corporate environmental management: A new industrial revolution. Academy of Management Perspectives, 12(2), 38-50. http://dx.doi.org/10.5465/ame.1998.650515

Brouthers, L.E., Werner, S., \& Matulich, E. (2000). The influence of triad nations' environments on price-quality product strategies and MNC performance. Journal of International Business Studies, 31(1), 39-62. http://dx.doi.org/ 10.1057/palgrave.jibs. 8490899

Chan, K.C. (1993). Intelligent corporate strategy: Beyond world-class manufacturing. Industrial Management \& Data Systems, 93(2), 1-64 http://dx.doi. org/10.1108/02635579310032824

Creelman, J. (1993). An act of faith. The TQM Magazine, 5(3), 15-18. http:// dx.doi.org/10.1108/EUM0000000003073

Cusumano, M.A., \& Takeishi, A. (1991). Supplier relations and management: A survey of Japanese, Japanese-transplant, and US auto plants. Strategic Management Journal, 12(8), 563-588. http://dx.doi.org/10.1002/smj.4250120802

Dahlgaard, J.J., \& Dahlgaard-Park, S.M. (2006). Lean production, six sigma quality, TQM and company culture. The TQM Magazine, 18(3), 263-281. http://dx.doi.org/10.1108/09544780610659998

Dahlgaard, J.J., Kristensen, K., Kanji, G.K., Juhl, H.J., \& Sohal, A.S. (1998). Quality management practices: A comparative study between East and West. International Journal of Quality \& Reliability Management, 15(8-1), 812826. http://dx.doi.org/10.1108/02656719810791675

De Miranda, A. (2003). Total quality management and inequality: The triple helix in global historical perspective. Science, Technology, \& Human Values, 28(1), 34-51. http://dx.doi.org/10.1177/0162243902238494

Deming, W.E., (1986). Out of the crisis. Cambridge, MA: Massachusetts Institute of Technology, Center for Advanced Engineering Study.

Fah, C.T. (1988). A total quality control programme for Dunlop Malaysia: The key issues. International Journal of Quality \& Reliability Management, 5(4), 7-16. http://dx.doi.org/10.1108/eb002909

Ferdows, K., Miller, J.G., Nakane, J., \& Vollmann, T.E. (1986). Evolving global manufacturing strategies: Projections into the 1990s. International Journal of Operations \& Production Management, 6(4), 6-16. http://dx.doi.org/10.1108/ eb054768 
Fisher, N., (2009). Homer Sarasohn and American involvement in the evolution of quality management in Japan, 1945-1950. International Statistical Review, 77(2), 276-299. http:/ / dx.doi.org/10.1111/j.1751-5823.2008.00065.x

Fruin, W.M., \& Nakamura, M. (1997). Top-down production management: A recent trend in the Japanese productivity-enhancement movement. Managerial and Decision Economics, 18(2), 131-139. http://dx.doi.org/ 10.1002/(sici)1099-1468(199703)18:2\%3C131::aid-mde815\%3E3.0.co;2-z

Garvin, D.A. (1986). Quality problems, policies, and attitudes in the United States and Japan: An exploratory study. Academy of Management Journal, 29(4), 653-673. http:/ / dx.doi.org/10.5465/255938

Gehani, R.R. (1993). Quality value-chain: A meta-synthesis of frontiers of quality movement. Academy of Management Perspectives, 7(2), 29-42. http://dx.doi. org/10.5465/ame.1993.9411302321

Goldman, H.H. (2005). The origins and development of quality initiatives in American business. The TQM Magazine, 17(3), 217-225. http://dx.doi. org/10.1108/09544780510594180

Hamzah, A., \& Ho, S. (1994). TQM training for small and medium industries in Malaysia. Training for Quality, 2(2), 27-35. http://dx.doi.org/10.1108/ 09684879410064365

Hatvany, N., \& Pucik, V. (1981). Japanese management practices and productivity. Organizational Dynamics, 9(4), 5-21. http://dx.doi.org/10.1016/00902616(81)90022-x

Herbig, P.A., \& Palumbo, F.A. (1996). Innovation - Japanese style. Industrial Management $\mathcal{E}$ Data Systems, 96(5), 11-20. http://dx.doi.org/10.5860/ choice.33-2212

Hill, F.M. (1989). What British management can reasonably expect from a quality circle programme. International Journal of Quality $\mathcal{E}$ Reliability Management, 6(3), http:/ / dx.doi.org/10.1108/02656718910134467

Hitomi, K., (1985). The Japanese way of manufacturing and production management, Technovation, 3(1), 49-55. http://dx.doi.org/10.1016/01664972(85)90036-7

Hitomi, K., (1992). Present trends and issues in Japanese manufacturing and management. Technovation, 12(3), 177-189. http://dx.doi.org/10.1016/ 0166-4972(92)90034-f

Ho, S.K. (1999). TQM and organizational change. The International Journal of Organizational Analysis, 7(2), 169-181. http:/ /dx.doi.org/10.1108/eb028899

Ho, S.K. (2010). Integrated lean TQM model for global sustainability and competitiveness. The TQM Journal, 22(2), 143-158 http://dx.doi.org/ 10.1108/17542731011024264

Ishikawa, A. (1985). Principles of QC circle activities and their effects on productivity in Japan: A corporate analysis. Management International Review, 25(3), 33-40.

Johnson, W.H., \& Chuang, M. (2010). A comparative innovation study of China, Japan and Taiwan. Chinese Management Studies, 4(4), 385-400. http:// dx.doi.org/10.1108/17506141011094154 
Juran, J.M., \& Godfrey, A.B. (1999). Juran's quality handbook. New York, NY: McGraw-Hill.

Kharbanda, O.P., \& Stallworthy, E.A. (1991). Company culture - its role in an industrial society. Industrial Management \& Data Systems, 91(2), 2-59. http://dx.doi.org/10.1108/02635579110004403

Khoo, H.H., \& Tan, K.C. (2003). Managing for quality in the USA and Japan: Differences between the MBNQA, DP and JQA. The TQM Magazine, 15(1), 14-24. http://dx.doi.org/10.1108/09544780310454402

Kidd, J.B. (1995). Subcontractors, JIT and kanbans: A brief review of spring manufacturing in Japan and South Korea. Integrated Manufacturing Systems, 6(6), 15-22. http://dx.doi.org/10.1108/09576069510099338

Kusago, T. (2007). Rethinking of economic growth and life satisfaction in postWWII Japan - A fresh approach. Social Indicators Research, 81(1), 79-102. http://dx.doi.org/10.1007/s11205-006-0016-9

Lee, J. (2014). Where imperialism could not reach: Chinese industrial policy and Japan, 1900-1940. Enterprise \& Society, 5(4), 655-671. http://dx.doi. org/10.1017/s1467222700016062

Lee, S.M., \& Ebrahimpour, M. (1984). Just-in-time production system: Some requirements for implementation. International Journal of Operations $\mathcal{E}$ Production Management, 4(4), 3-15. http://dx.doi.org/10.1108/eb054721

Leitner, P.M. (1999). Japan's post-war economic success: Deming, quality, and contextual realities. Journal of Management History, 5(8), 489-505. http:// dx.doi.org/10.1108/13552529910290539

Liker, J.K., Kamath, R.R., \& Wasti, S.N. (1998). Supplier involvement in design: A comparative survey of automotive suppliers in the USA, UK and Japan. International Journal of Quality Science, 3(3), 214-238. http://dx.doi. org/10.1108/13598539810229212

Lim, K.K., Ahmed, P.K., \& Zairi, M. (1999). Managing waste and looking beyond: The IMI approach. The TQM Magazine, 11(5), 304-310. http:// dx.doi.org/10.1108/09544789910282354

Linner, T., \& Bock, T. (2012). Evolution of large-scale industrialisation and service innovation in Japanese prefabrication industry. Construction Innovation, 2(2), 156-178. http://dx.doi.org/10.1108/14714171211215921

Macdonald, J. (1984). The quality challenge. International Journal of Quality $\mathcal{E}$ Reliability Management, 1(3), 36-41. http:/ /dx.doi.org/10.1108/eb002834

Macdonald, J. (1987). The Japan of Europe: Which country will earn the title? Management Decision, 25(1), 38-42. http://dx.doi.org/10.1108/eb001433

Mahon, W.A., \& Dyck, R.E. (1982). Japanese quality systems from a marketing viewpoint. Industrial Management \& Data Systems, 82(9/10), 8-14. http:// dx.doi.org/10.1108/eb057276

McMillan, J. (1990). Managing suppliers: Incentive systems in Japanese and US industry. California Management Review, 32(4), 38-55. http://dx.doi. org $/ 10.2307 / 41166627$ 
Munchus III, G. (1983). Employer-employee based quality circles in Japan: Human resource policy implications for American firms. Academy of Management Review, 8(2), 255-261. http://dx.doi.org/10.2307/257753

Ohno, K. (2006). The economic development of Japan: The path traveled by Japan as a developing country. Tokyo, Japan: GRIPS Development Forum.

Oliver, N., Delbridge, R., \& Lowe, J. (1996). The European auto components industry. International Journal of Operations \& Production Management, 16(11), 85-97. http://dx.doi.org/10.1108/01443579610131474

Perman, D.C. (1989). Training, problem solving and quality improvement - some forgotten lessons from Japan. International Journal of Quality $\mathcal{E}$ Reliability Management, 6(6). http://dx.doi.org/10.1108/02656718910134269

Petersen, P.B. (1993). The light before the dawn: The origin of quality Japanese products during the 1920s. Journal of Managerial Issues, 5(1), 17-38.

Phan, A.C., Abdallah, A.B., \& Matsui, Y., (2011). Quality management practices and competitive performance: Empirical evidence from Japanese manufacturing companies. International Journal of Production Economics, 133(2), 518529. http://dx.doi.org/10.1016/j.ijpe.2011.01.024

Pudelko, M., \& Mendenhall, M.E. (2007). The Japanese management metamorphosis: What western executives need to know about current Japanese management practices. Organizational Dynamics, 36(3), 274-287.

Reitsperger, W.D., \& Daniel, S.J. (1990). Dynamic manufacturing: A comparison of attitudes in the USA and Japan. MIR: Management International Review, 30(3), 203-216.

Robinson, A.G., \& Schroeder, D.M. (1993). Training, continuous improvement, and human relations: the US TWI programs and the Japanese management style. California Management Review, 35(2), 35-57. http://dx.doi.org/ $10.2307 / 41166721$

Saha, A. (1992). Zen and industrial management in Japan. Journal of Managerial Psychology, 7(3), 3-9. http://dx.doi.org/10.1108/eum0000000001736

Salleh, N.A.M., Kasolang, S., \& Jaafar, A. (2012). Review study of developing an integrated TQM with LM framework model in Malaysian automotive industry. The TQM Journal, 24(5), 399-417. http://dx.doi.org/10.1108/ 17542731211261566

Smith, J. (1993). Japan - myth or miracle? The TQM Magazine, 5(2), 47-51 http:/ / dx.doi.org/10.1108/eum0000000003071

Sohal, A.S. (1998). Assessing manufacturing/quality culture and practices in Asian companies. International Journal of Quality \& Reliability Management, 15(8-1), 920-930. http://dx.doi.org/10.1108/02656719810199015

Tattersall, J. (1989). Implementing total quality management with action learning. International Journal of Public Sector Management, 2(3), 47-55. http://dx.doi.org/10.1108/09513558910000176

Tranfield, D., Denyer, D., \& Smart, P. (2003). Towards a methodology for developing evidence-informed management knowledge by means of systematic 
review. British Journal of Management, 14(3), 207-222. http://dx.doi. org/10.1111/1467-8551.00375

Trevor, M., (1986). Quality control-learning from the Japanese. Long Range Planning, 19(5), 46-53. http:/ / dx.doi.org/10.1016/0024-6301(86)90008-7

Vuppalapati, K., Ahire, S.L., \& Gupta, T. (1995). JIT and TQM: A case for joint implementation. International Journal of Operations \& Production Management, 15(5), 84-94. http:// dx.doi.org/10.1108/01443579510083686

Westbrook, R. (1995). Organizing for total quality. International Journal of Quality \& Reliability Management, 12(4), 8-25. http://dx.doi.org/10.1108/ 02656719510087292

Woodworth, J.N. (1991). International perspective: Japan's economic outlook: revving up the export machine. Business Economics, 26(4), 40-45.

Zairi, M. (1994). TQM: What is wrong with the terminology. The TQM Magazine, 6(4), 6-8. http://dx.doi.org/10.1108/09544789410062713

Zeng, J., Phan, C.A., \& Matsui, Y. (2015). The impact of hard and soft quality management on quality and innovation performance: An empirical study. International Journal of Production Economics, 162, 216-226. http://dx.doi. org/10.1016/j.ijpe.2014.07.006

Zhang, G.P., \& Xia, Y. (2013). Does quality still pay? A reexamination of the relationship between effective quality management and firm performance. Production and Operations Management, 22(1), 120-136. http://dx.doi.org/ 10.1111/j.1937-5956.2012.01341.x

Zhao, X., Maheshwari, S.K., \& Zhang, J. (1995). Benchmarking quality practices in India, China and Mexico. Benchmarking for Quality Management $\mathcal{E}$ Technology, 2(3), 20-40. http://dx.doi.org/10.1108/14635779510099220 
